\title{
Deming's chain reaction revisited
}

\section{Andrés Carrión-Garcia* and Angela M. Grisales}

Centre for Quality and Change Management, Universitat Politecnica de Valencia,

Edif. 7 A, 46022, Valencia, Spain

Email: acarrion@upv.es

Email: angride1@upv.es

*Corresponding author

\section{Ljubisa Papic}

Faculty of Technical Sciences of Cacak, University of Kragujevac,

Cacak, Serbia

and

Dependability and Quality Management Research Centre,

Prijevor, Serbia

Email: dqmcenter@open.telekom.rs

\begin{abstract}
Deming's chain reaction is a well-known proposal from Dr. W.E. Deming, in which he explains the positive effect of improving quality in different aspects of an organisation's activities and performance. Recognising and enhancing the value of Deming ideas, in this paper chain reaction is reevaluated and adapted to environments different to those considered by Deming, specifically to those where competition is not the motto for quality improvement. Three economic situations are considered: open competitive markets (as Deming considered); markets with no or very limited competition; and public services or organisations not oriented to profits but to cover social demands. Two additional versions of the chain reaction are proposed based in Deming's original, and finally a comprehensive chain reaction is presented, adequate to any type of economic environment. The paper enhances the strength and power of Deming's ideas, showing its ability to adapt to scenarios different to those originally considered.
\end{abstract}

Keywords: quality management; Deming's chain reaction; non-competitive environment; quality in non-profit organisations.

Reference to this paper should be made as follows: Carrión-Garcia, A., Grisales, A.M. and Papic, L. (2017) 'Deming's chain reaction revisited', Int. J. Productivity and Quality Management, Vol. 21, No. 2, pp.264-271.

Biographical notes: Andrés Carrión-Garcia is an Associate Professor in the Universidad Politecnica de Valencia (Spain) where he is the Head of the Research Centre for Quality and Change Management and Coordinator of the Master Program in Data Analysis Engineering. He has worked in fields related with quality, both from the perspectives of statistical methods and management. He has published in the fields of quality, engineering and statistics, and has 
acted as international consultant in quality and statistics. He has also a long experience in cooperating with industrial companies, mainly in the automotive sector.

Angela M. Grisales is a researcher in the Centre for Quality and Change Management in the Universidad Politecnica de Valencia (UPV) (Spain). She has also a Diploma of Specialist in Quality Management and Control by the UPV. She has worked in the field of quality with special emphasis in quality in higher education institutions.

Ljubisa Papic is a Professor in the Faculty of Technical Sciences in Çaçak (Serbia) and the Head of the Dependability and Quality Management Research Center in Prijevor (Serbia). He has a long experience in the field of quality, both from the academy and from the industrial perspectives. He has worked with automotive industry, mining companies and others, always applying quality tools and techniques.

This paper is a revised and expanded version of a paper entitled 'Quality and sustainability: the Deming's chain reaction' presented at the International Conference on Dependability and Quality Management, Prijevor, Serbia, 25-26 June 2015.

\section{Introduction}

One of the main reasons for all quality efforts in business is the long-term survival of organisations, thus positively serving the community (customers and other stakeholders).

This fact was thoroughly understood by Deming, and in his books and lectures, he insisted on this survival as the goal for any organisation, as opposed to the short-term search for profit.

He explained his ideas clearly and these explanations have become one of the fundamentals in the world of quality. One of his best-known contributions is Deming's chain reaction [Deming, (1986), chapter 1].

Over the years, many publications have studied the subject of the Deming's chain reaction. Without doing an exhaustive state of the art review, some comments can be adequate at least to show how this subject has been studied over the years. Most publications have a qualitative approach, and are in great part papers and books commenting and explaining the chain reaction, its consequences and its relations with other quality issues (as total quality management, ISO 9000,...). This is the case for most of the publications in the 90's. For instance, Anderson et al. (1994) discuss about the Deming management method and cite the chain reaction in the context of the relation between costs and quality. More recently, Grigg and Walls (2007) in a paper centred in the food industry comment that case studies and surveys show that benefits of quality models typically follow Deming's chain reaction scheme, presenting a detailed map of benefits related with quality models that, in their words, are broadly in line with Deming's chain reaction.

Some papers have followed a different line of research, with a quantitative approach to Deming's chain reaction. This is the case of Hendricks and Singhal (1997), who present an empirical study showing statistical evidence of the relationship between the implementation of TQM programs and the operating performance of the firms. Samson 
and Terziovski (1999) present an empirical study on the relationship between TQM practices and operational performance, identifying leadership, management of people and customer focus as the predictors of operational performance. Wayhan et al. (2010), in this and in at least other two papers, study alternative quantitative models to evaluate impacts of quality in financial performance, starting from the Deming's model to conclude that these impacts are primarily indirect in nature.

Nevertheless, none of the papers we have reviewed considers situations in which competition is not in the centre of the economic activity of companies, and the impact of this fact in Deming's chain reaction. The aim of this paper is to contribute to those research efforts showing the strength and power of Deming's chain reaction, when applying it to different economic environments.

\section{The classical Deming's chain reaction}

With his chain reaction, Deming (1986, chapter 1) clearly states the impacts that quality improvement generates in the organisation (see Figure 1).

Figure 1 Deming's chain reaction

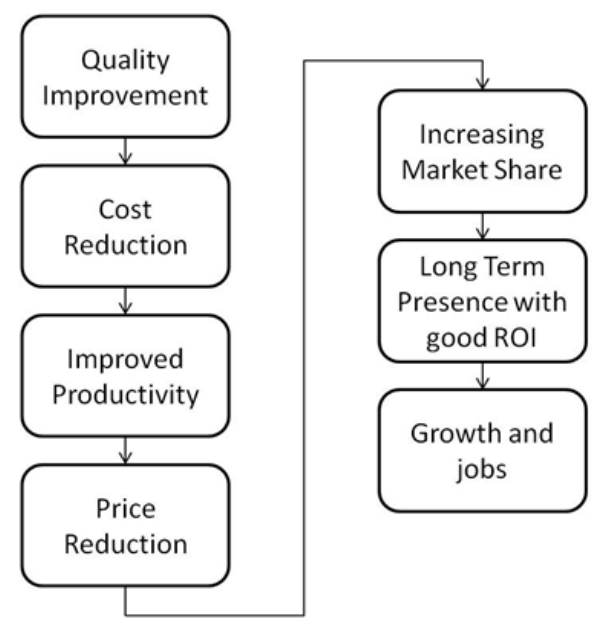

Source: According to Deming (1986)

The first result of improving quality (after probably a lot of hard work by people in the organisation), is increased productivity. This improvement is the expected (and almost unavoidable) effect of doing things right first time, with no retouching or reworking, no time-wasting, considerable scrap reduction, as well as other improvements in the organisation's performance.

Better productivity implies lower production costs. The question is not to produce more, but to produce more effectively, and thus produce more economically. Cost reduction allows companies to decrease prices, and to exploit improved effectiveness as an advantage in a competitive world.

The natural effect of reducing prices, according to classical economic theory, is increased sales, thus gaining market share and widening the company's presence in markets. Deming emphasises the true aim of the organisation at this point: long-term 
survival, understood as a long-term profitable presence in the market, with good return on investment (ROI).

Finally, the increase in market share means growth for the company, which may need to hire additional staff, thus contributing to community development and increased welfare.

\section{Deming's chain reaction and economic environment}

When Deming put forward this famous chain reaction, he was thinking about companies working in a competitive environment, as is the case of most US and European industrial and service companies. For this situation, the competitive advantages generated by quality improvements (as shown by the chain reaction) can be crucial for growth and even survival of companies.

However, there are other economic and social situations, where competition among companies is not the key to their activities, and sometimes profits are not their raison d'être. Thus, in the case of some companies, it is difficult to fit their situation and activity into Deming's chain reaction. This is the case, for example, of public-sector companies, public services, and non-profit organisations.

Does this mean that Deming's chain reaction does not apply to these organisations? Definitely not. The strength of Deming's idea makes it applicable to different economic environments. However, some re-writing may be needed and some steps of the chain may need to be redefined.

In the following lines, we will review how the basic chain reaction can be adapted to two different situations:

- non-competitive environments, where companies look for profits in a situation of weak competition or even with total absence of competition

- $\quad$ public services and non-profit organisations, where organisations are not oriented to profits but to cover a social demand.

\section{Deming's chain reaction in non-competitive environments}

This is the situation in which monopolistic organisations live. It is also the situation for companies in theoretically open markets, in which geographical, technical or commercial issues mean that competition is weak or non-existent. Some practices (frequently on the edge of legality) in oligopolistic markets produce a similar environment in which competition does not exist.

Some examples can be cited in different economic sectors: the Israeli wine industry was in this situation as a wine-grape cooperative controlled $75 \%$ of the market (Golan and Shalit, 1993). Highly regulated sectors, as the banking sector in Turkey with an important presence of State owned banks, are another example (Yavas et al., 1997). A last example can be the relevance of non-competitive options of urban public transport that remain essential features, especially in Europe (Beck, 2012).

Apart of these specific examples, Deming mentions in chapter 12 of his book 'Quality, Productivity and Competitive Position' (Deming, 1982), that frequently service establishments have a captive market (Deming also mentions this in chapter 7 of his book 
Out of the Crisis, Deming, 1986). This can be considered as another situation of non-competitive environment.

Thus, what happens when a company does not have competitors? Does the chain reaction continue to work? How a lack of competition does affect its steps?

The first three steps of the chain remain unchanged: well addressed quality efforts will always produce cost reductions, and this automatically implies improving productivity. Differences start in the fourth step: without competition, are there any advantages of reducing prices? Or, if we are the only company in market, can we really increase market share? If the answer to these two questions is yes, then Deming's standard chain reaction applies directly. In these cases, reducing prices can make our product or service accessible to segments of the market that could not previously afford them, and this will produce growth and long-term presence in the market.

However, if the answer to these two questions was negative, then the chain would seem to break at this point. But in fact, the chain does not really break; it simply does not need to be as long. In this case, the effect of reducing costs and improving productivity is transferred directly to the organisation's economic results, increasing profits and helping to achieve long-term presence in the market, but maybe without growing or creating new jobs. We must consider that at least the robustness of the organisation is improved.

For this situation, Deming's chain reaction can be redrawn as shown in Figure 2.

Figure 2 Deming's chain reaction for non-competitive environments

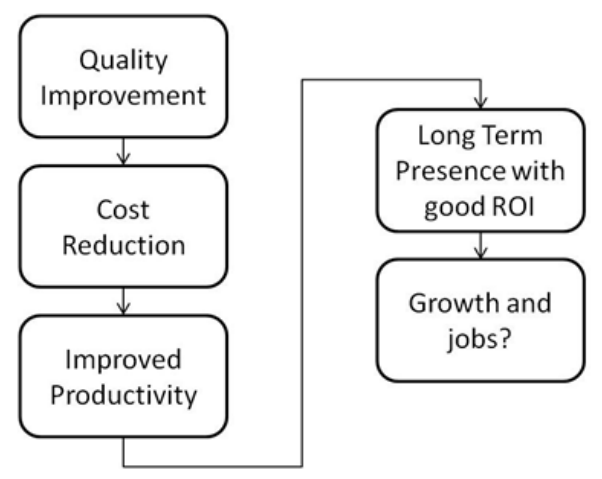

\section{Deming's chain reaction in public services and non-profit organisations}

Public services, such as public healthcare systems and public educational institutions, do not have the pressure of competition. Nevertheless, if they are well-managed, such organisations must look for quality and effectiveness (in terms of achievement of its goals). 'Public' should not mean inefficient or low quality, and quality tools have an important role in achieving first class standards in those services. Pressure here can be established by accountability systems and transparency. In non-profit organisations, again market competition is not at the root of the efforts to improve and become more effective. There may be competition for public or private resources, or it may simply be a question of using the resources available as best as possible. Quality tools are again in the front line on the road to success. 
How does Deming's chain reaction perform now? Again, the three first steps remain unchanged. In the fourth step, as in the previous case but for different reasons, price reduction may not make sense and increasing market share may be impossible (sometimes fixed by regulatory institutions). Thus, after cost reduction and improved productivity, different consequences and different steps should be considered in the chain. As opposed to the previous case, this is not only a question of eliminating some steps in the chain. It is actually a question of replacing some steps with others, which are more suitable to this environment.

Figure 3 Deming's chain reaction for non-profit organisations

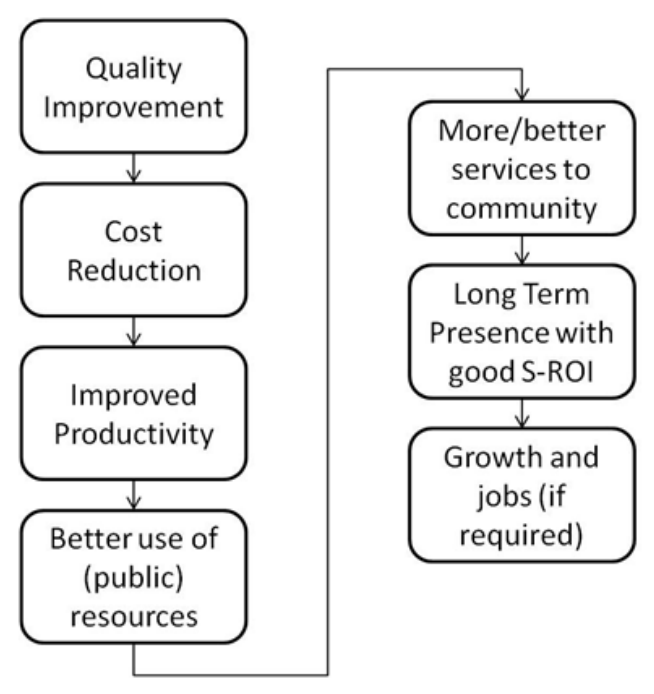

Figure 3 shows how the chain reaction can be adapted. After reducing costs and increasing productivity, what follows is better use of the available resources (maybe public funds). This allows organisations to better serve the community, providing greater number of improved services which, together with recognised good use of resources, helps organisations to stay in the market (if this term is suitable) with what we can call good social-return on investment (S-ROI). If this is required by the organisation, and in terms of social environment characteristics, growth and the creation of new jobs are an option.

\section{Deming's chain reaction in multiple environments}

Can these three chain reactions be integrated into one structure? An attempt to do so is presented in Figure 4, in what we have called, Deming's chain reaction in multiple environments. Some changes have been made in the order of the original steps.

In this version, there is a common end for the three cases: to stay in the market, i.e., the long-term permanence of the organisation in the market. ROI can be understood as a means to achieving this goal. This is coherent with Deming's ideas about the importance of the will to prevail in the market, and the importance given to long-term efforts and 
planning. Thus, we have separated this long-term permanence and the ROI (or S-ROI). The rest of elements remain the same as those in Figures 1 to 3.

Figure 4 Integrated multi-environment Deming's chain reaction

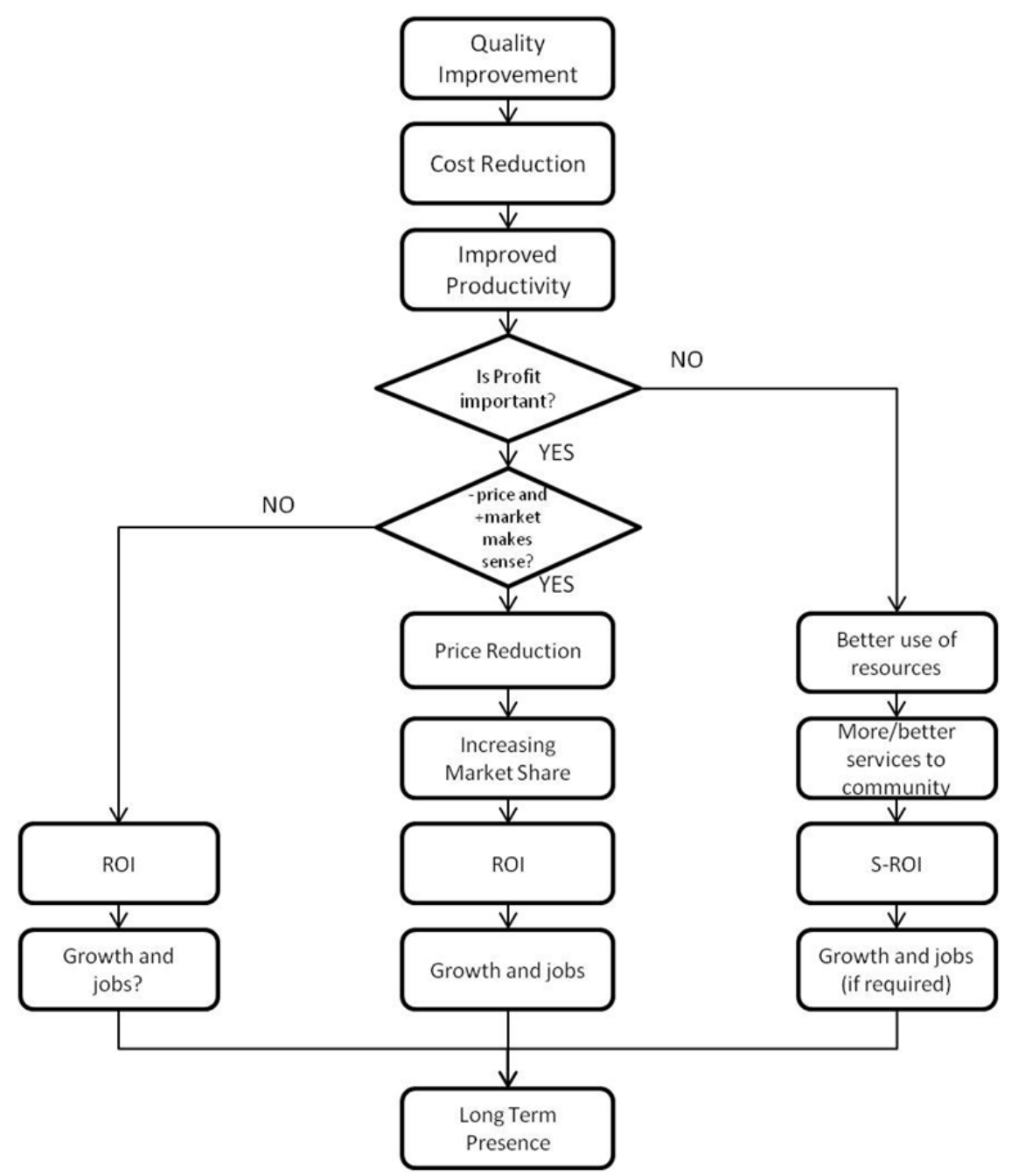

The right branch corresponds to environments in which organisations do not look for economic profit, that is, public services, NGOs, and non-profit organisations, in general.

The left branch applies in non-competitive environments in which it makes no sense for organisations to reduce prices and increase their market share, and where growth and job creation will probably not occur.

Finally, the central column corresponds to Deming's original proposal, for organisations living in a competitive environment, where every opportunity to get ahead of the competition must be exploited.

In all three environments, the common goal of organisations is to stay in the market and to continue serving the community as best as possible. 


\section{Final comments}

Classical Deming's chain reaction fits very well with the situation in competitive markets, when companies and organisations need to take advantage of their own strengths, especially the improvement of their processes and products quality, to continue being competitive and profitable. In this paper, we have shown that in non-competitive environments Deming's chain reaction is also capable of explaining the benefits of quality improvement for different organisations.

After years of successful application, the value of Deming ideas does not need to be proven. Adapting these ideas to environments different to those considered by Deming, we have illustrated this value.

\section{References}

Anderson, J.C., Rungtusanatham, M. and Schroeder, R.G. (1994) 'A theory of quality management underlying the Deming management method', Academy of Management Review, Vol. 19, No. 3, pp.472-509.

Beck, A. (2012) Competition for Public Transport Services, pp.81-92, Springer-Verlag Berlin Heidelberg.

Deming, W.E. (1982) Quality, Productivity and Competitive Position, Massachusetts Institute of Technology Press, Cambridge, MA.

Deming, W.E. (1986) Out of the Crisis, Massachusetts Institute of Technology Press, Cambridge, MA.

Golan, A. and Shalit, H. (1993) 'Wine quality differentials in hedonic grape pricing', Journal of Agricultural Economics, Vol. 44, No. 2, pp.311-321.

Grigg, N.P. and Walls, L. (2007) 'Developing statistical thinking for performance improvement in the food industry', International Journal of Quality \& Reliability Management, Vol. 24, No. 4, pp.347-369.

Hendricks, K.B. and Singhal, V.R. (1997) 'Does implementing a TQM program improve operating performance?', Management Science, Vol. 43, No. 9, pp.1258-1274.

Samson, D. and Terziovski, M. (1999) 'The relationship between total quality management practices and operational performance', Journal of Operations Management, Vol. 17, No. 4, pp.393-409.

Wayhan, V.B., Khumawala, B.M. and Balderson, E.L. (2010) 'Empirical enhancements to Deming's chain reaction model', Total Quality Management \& Business Excellence, Vol. 21, No. 7, pp.779-789.

Yavas, U., Bilgin, Z. and Shemwell, D.J. (1997) 'Service quality in the banking sector in an emerging economy: a consumer survey', International Journal of Bank Marketing, Vol. 15, No. 6, pp.217-223. 